\title{
RUANG APRESIATIF, REKREATIF DAN KREATIF
}

\author{
Eileen Rosabel Renaningtyas ${ }^{1)}$, Tatang Hendra Pangestu ${ }^{2)}$
}

1) Program Studi S1 Arsitektur, Fakultas Teknik, Universitas Tarumanagara, eileenrosabel@gmail.com

2) Program Studi S1 Arsitektur, Fakultas Teknik, Universitas Tarumanagara, tatang_pangestu@hotmail.com

\begin{abstract}
Abstrak
Tempat ketiga sebagai tempat berkumpulnya masyarakat, dimana dapat menerima berbagai kalangan masyarakat, tidak menutup kemungkinan untuk memisahkan kegiatan masyarakat dalam bersenang-senang sambil bekerja. Kelurahan Cilandak Barat yang menjadi kawasan terpilih sangat berkaitan dengan ekonomi kreatif. Menurut data BPS Kelurahan Cilandak Barat, sektor usaha informal merupakan kegiatan ekonomi yang dominan dilakukan warga. Jenis usaha yang dilakukan bervariasi mulai dari usaha warung kelontong, usaha wartel, usaha warnet, usaha matrial, usaha salon, hingga usaha tanaman hias. Ekonomi kreatif akan dipilih sebagai tema utama yang diangkat dari latar belakang kawasan. Tema ini bertujuan sebagai upaya meningkatkan kesejahteraan masyarakat, khusunya pada kawasan terpilih. Fungsi proyek ini sebagai tempat untuk memfasilitasi masyarakat Cilandak sebagai tempat edukasi, tempat berinovasi maupun berkreasi dan tempat beristirahat bagi para pengunjung yang datang dalam mengekspresikan diri. Dalam mengkaji literatur terdapat beberapa faktor yang menentukan yaitu memaksimalkan pedestrian pada lantai dasar, terdapat jembatan sebagai penghubung antar massa dan bentuk massa dalam menanggapi lingkungan sekitar yang menjadi faktor terbesar dalam mempengaruhi bentuk massa. Maka dari itu, metode dalam pembentukan sebuah massa dengan menggunakan sistem analisa tapak. Analisa tapak terdiri dari, analisa view, skyline, in \& out tapak, zonning, respon arah pejalan kaki dan kendaraan. Hasil dari analisa yang didapat akan menghasilkan bentuk massa, dan hasil analisa tapak akan terlihat pada denah, tampak dan potongan.
\end{abstract}

Kata kunci: analisa tapak; ekonomi kreatif; tempat ketiga

\begin{abstract}
Third place as community gathering place, which can accept various people, do not close the possibility to separate community activities in having fun while working. The village of Cilandak Barat which became the chosen region is very related to the creative economy. According data BPS West Cilandak Village, the informal business sector is the dominant economic activity of citizens. The type of business done varies from the business of grocery stalls, business Wartel, Cyber Cafe business, Matrial Business, salon business, to the business of ornamental plants. The creative economy will be chosen as the main theme raised from the region's background. This theme aims to improve people's welfare, especially in selected regions. This project functions as a place to facilitate the people of Cilandak as an educational place, a place to innovate and create and a place to rest for the visitors who come in expressing themselves. In reviewing the literature there are several determining factors that maximize pedestrian on the ground floor, there is a bridge as a liaison between mass and mass form in response to the surrounding environment which is the biggest factor in affect the mass form. Therefore, the method in the formation of a mass using the site analysis system. Site analysis consists of, view analysis, Skyline, in \& out tread, zonning, pedestrian and vehicle directional response. The result of the analysis will result in a mass form, and the result of the analysis of the site will be visible on the floor, look and cut.
\end{abstract}

\section{Keywords: creative economy; site analysis; third place}




\section{PENDAHULUAN}

Koridor TB Simatupang yang akan menjadi CBD, akan memberi identitas baru yakni terbangunnya perusahaan besar dimana terdapatnya tenaga ahli dan pekerja yang berpendidikan tinggi sehingga akan terjadinya daya saing yang tinggi. Koridor TB Simatupang yang menjadi bagian dari kawasan Cilandak, tepatnya di Kelurahan Cilandak Barat turut memberi pengaruh besar dalam pandangan masyarakat terhadap image kawasan Cilandak.

Menurut data BPS Kelurahan Cilandak Barat, sektor usaha informal merupakan kegiatan ekonomi yang dominan dilakukan warga. Jenis usaha yang dilakukan bervariasi mulai dari usaha warung kelontong, usaha wartel, usaha warnet, usaha matrial, usaha salon, hingga usaha tanaman hias. Usaha warung kelontong menempati urutan teratas dalam jenis usaha yang paling sering dilakukan oleh warga Cilandak Barat.

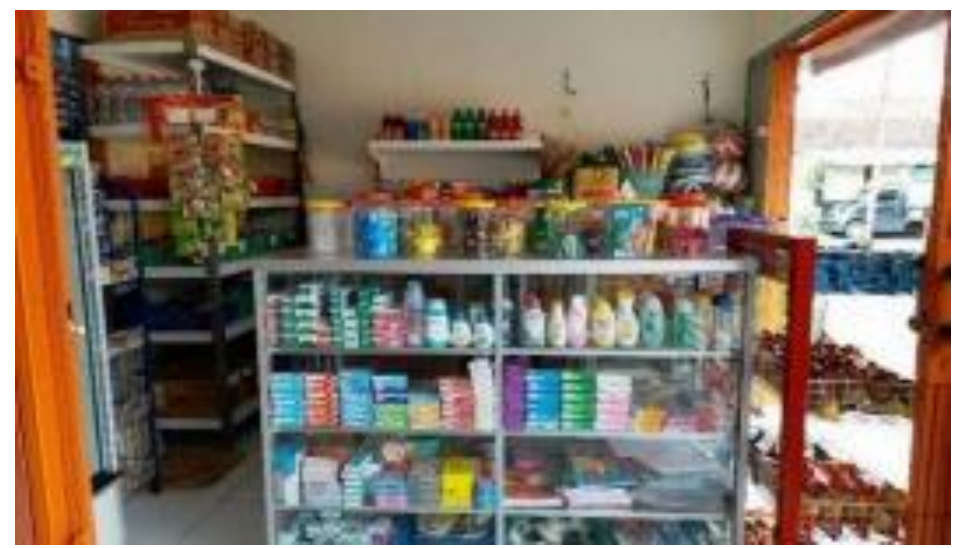

Gambar 1. Warung Kelontong di Cilandak Barat Sumber: https://www.google.com/

Dibawah ini merupakan data penduduk berdasarkan Jakarta Smart City dengan batasan wilayah penduduk Kelurahan Cilandak Barat.

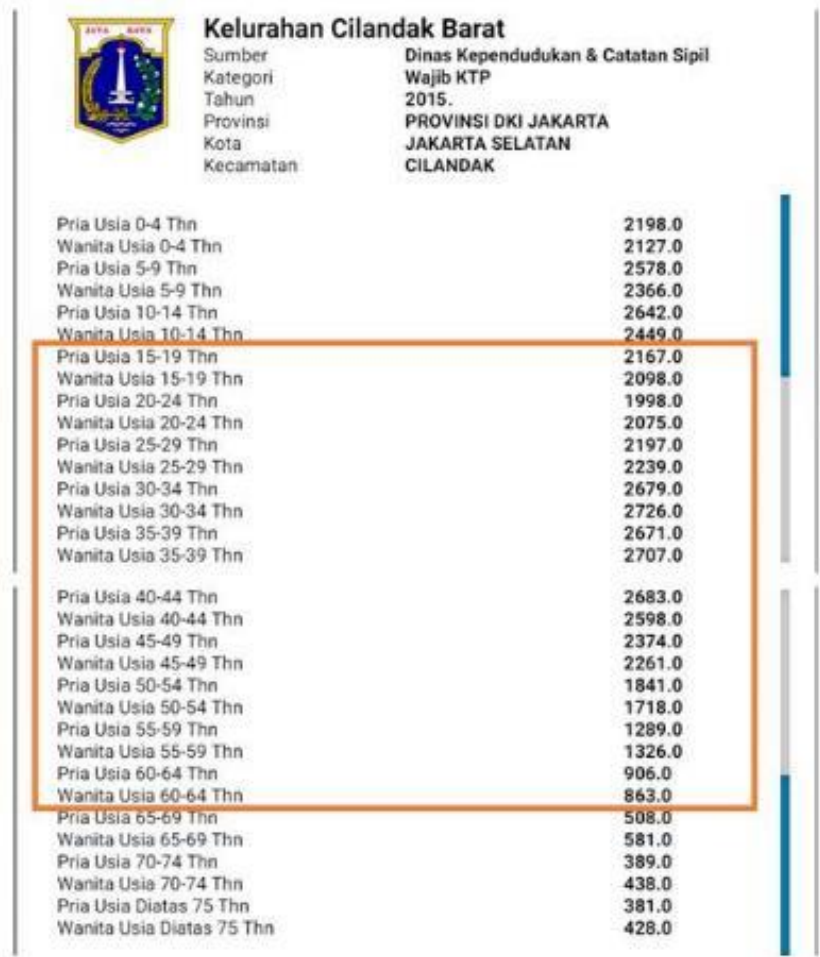

Gambar 2. Solusi Dalam Menyelesaikan Hambatan Sumber: https://smartcity.jakarta.go.id 
Dalam data yang dipaparkan Badan Pusat Statistik (BPS), kelompok usia produktif dari berusia 15-64 tahun. Dikaitkan menurut data Kelurahan Cilandak Barat, jumlah penduduk Cilandak Barat mayoritas adalah penduduk usia produktif, yaitu sebanyak 41.416 jiwa. Adapun penduduk usia muda (15-39 tahun) di wilayah ini termasuk mayoritas di antara kelompok usia lainnya yaitu sebanyak 23.557 jiwa. Penduduk usia anak-anak (0-14 tahun) sebanyak 14.360 jiwa. Penduduk usia madya (40-59 tahun) adalah sebanyak 16.090 jiwa. Sementara penduduk usia tua (60-75 tahun ke atas) adalah sebanyak 4494 jiwa.

Dengan banyaknya usia produktif di Kecamatan Cilandak Barat dengan usaha yang dijalankan perlu diarahkan pada penggalian potensi masyarakat terutama bidang ekonomi kreatif. Hal ini dilakukan mengingat pembinaan ekonomi lemah berbasis masyarakat sangat dibutuhkan dalam upaya meningkatkan kesejahteraan masyarakat. Masyarakat Cilandak perlu membangun kreativitas sehingga memiliki daya saing yang tinggi dan tidak terjadinya kesenjangan sosial, meliputi;

- Membuka bisnis baru (wirausaha).

- Menambah wawasan.

- Taraf edukasi bagi segala umur.

Selain perumahan dan gedung perkantoran yang berdiri, terdapat pusat perbelanjaan yang menimbulkan gaya hidup (lifestyle center) di kawasan ini. Kini kawasan TB Simatupang telah menjadi kawasan bisnis dan gaya hidup baru (C, 2012).

\section{KAJIAN LITERATUR}

\section{Teori space dan place}

Istilah place erat kaitannya dengan teori space. Jika space berarti tiga dimensi yang membentuk place, sedangkan karakter diartikan sebagai suasana dari sebuah place. Edward Relp, Prospect of place, berpendapat bahwa ada hubungan antara lanskap, pengalaman keseharian dengan faktor sosial dan ekonomi dalam pembentukan sebuah ruang. Istilah place dikaitkan dengan hubungan antara lanskap, pengalaman keseharian dengan faktor sosial sebagai tempat-tempat yang unik, lanskap, ruang-ruang komunal dibandingkan dengan pengalaman dan lingkungan tertentu (Larice dan Macdonad, 2007).

Dalam terjadinya suatu place, terdapat suatu hubungan yang tidak terlihat antara suatu space dengan setiap tubuh individu maupun kelompok (Yi-Fu Tuan, Space and Place : Humanistic Perspective). Persepsi visual, sentuhan, gerakan, dan pemikiran bergabung untuk memberikan rasa ruang yang khas. Pengenalan suatu tempat dapat dirasakan setelah terjadinya perlakuan dari gerakan tubuh yang dapat dilihat dari adanya hubungan jarak antara objek, yang berarti terdapat hubungan antara Space and the body. Sehingga space selalu merupakan hasil dari proses pemikiran dan representasi.

Dalam suatu place dapat ditemukan ruang yang sepenuhnya abstrak atau difokuskan kepada kegiatan apa yang akan dilakukan dalam ruang. Di luar pengalaman antara individu dengan objek, suatu space dapat berubah menjadi place jika adanya suatu kelompok yang saling berinteraksi walaupun tanpa adanya suatu objek. Place mengandung unsur pengalaman langsung, mempunyai arti dan merupakan sesuatu yang nyata yang didalamnya terdapat aktivitas yang terjadi terus menerus. Sehingga keberadaan Place sangatlah penting karena merupakan sumber dari sebuah identitas yang menunjukkan eksistensi individu maupun komunitas.

\section{Teori Tempat Ketiga (Third Place)}

Menurut Ray Ouldenburg, istilah Third Place adalah istilah yang umum untuk menandakan tempat-tempat publik yang diadakan secara tetap, sukarela, informal untuk kegiatan informal, seperti berkumpul bersama keluarga atau teman (Larice dan Macdonad, 2007). Berfokus pada pengalaman seperti suatu place akan lebih mementingkan "apa yang tidak terlihat" dalam suatu fisik suatu bangunan, tetapi pada imajinasi, representasi dan pengalaman kegiatan yang dirasakan yang menghasilkan nilai tambah suatu tempat tersebut. Istilah Third Place hanya 
mengarah kepada tempat-tempat hangout seperti kafe dan bar. Padahal istilah Third Place juga mengarah pada ruang-ruang terbuka kota, seperti taman kota, plaza, dan sidewalk dimana masyarakat dapat menghabiskan waktu untuk berkumpul dengan saudara atau teman-teman sambil menikmati suasana kota. Oleh Karena itu Third Place juga disebut sebagai a public meeting place (Larice dan Macdonad, 2007).

\section{Karakteristik}

a. Neutral, tempat yang netral bagi seluruh kalangan masyarakat dan tidak terikat pada finansial, politik, hukum, atau lainnya.

b. They are level, tidak ada syarat/status sosial untuk berpartisipasi dengan penerapan bentuk yang sederhana.

a. Conversation is the main activity, tempat yang mengutamakan interaksi sosial antar pengunjung.

b. Accessible, terbuka, mudah diakses dan memenuhi kebutuhan masyarakat.

c. Have regulars, memberikan wadah untuk membantu interaksi sosial sehingga tempat ketiga mempunyai pengunjung yang mempunyai kebutuhan untuk datang ke tempat ketiga.

d. Physically plain and unpretentious, pengunjung Third Place memiliki rasa hangat tanpa adanya kepemilikan pada bangunan dan pengunjung merasa bebas dalam menunjukkan jati diri.

e. Playful, suasana yang menyenangkan sehingga membangun rasa nyaman serta menjadi daya tarik bagi lingkungan sosial.

\section{Tempat ketiga (third place) sebagai kebutuhan}

Sebagai tempat ketiga masyarakat, harus memberi pengaruh dalam kebutuhan masyarakat dalam perkembangan kehidupan sosial ekonomi. Dibawah ini merupakan teori kebutuhan Maslow.

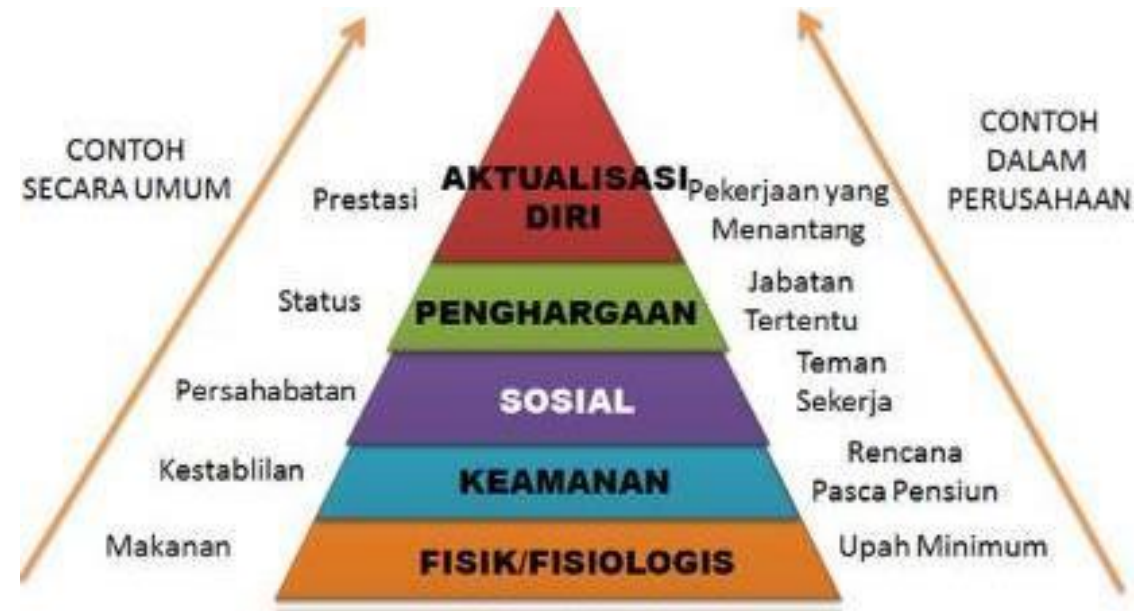

Gambar 3. Teori Hirarki Kebutuhan Maslow

Sumber: http://indraallen.blogspot.com/

\section{Teori Open Architecture}

Open architecture sebagai third place dapat didefinisikan dengan melihat hal-hal penting yang terkait dengan konteks kebutuhan masyarakat kota dan modernitas yang berorientasi pada teknologi, informasi dan individu. Open architecture yang merupakan the third place bagi masyarakat adalah tempat dimana sebagai ruang antara, berarti bukan sebagai tempat tinggal dan bukan tempat berkerja. Ruang antara dalam konteks ruang publik, menjadi tantangan utama untuk membantu masyarakat kota agar bersifat humanis, terbuka, dinamis dan produktif. Sehingga dalam mendesain suatu open architecture perlu adanya pemikiran kritis untuk mengatur area publik dan private serta area terbuka dan tertutup. 
Ruang terbuka (Open Space) merupakan ruang terbuka yang selalu terletak di luar massa bangunan yang dapat dimanfaatkan dan dipergunakan oleh setiap orang serta memberikan kesempatan untuk melakukan bermacam-macam kegiatan. Yang dimaksud dengan ruang terbuka antara lain jalan, pedestrian, taman lingkungan, plaza, lapangan olahraga, taman kota dan taman rekreasi. Menurut Lao Tze adalah bukan hanya sesuatu yang dibatasi secara fisik oleh lantai, dinding dan langit-langit, tetapi "kekosongan" yang terkandung di dalam bentuk pembatas ruang tadi.

\section{Public Space}

Dalam mengevaluasi ribuan ruang publik di seluruh dunia, PPS (Project for Public Space) telah menemukan solusi untuk menjadikan ruang publik yang sukses, mereka umumnya memiliki empat standart kualitas untuk menjadi ruang publik yang hidup dan bermanfaat dengan berkembangnya kehidupan sosial ekonomi masyarakat. Diagram PPS dapat dilihat pada gambar 2.2 dibawah ini.

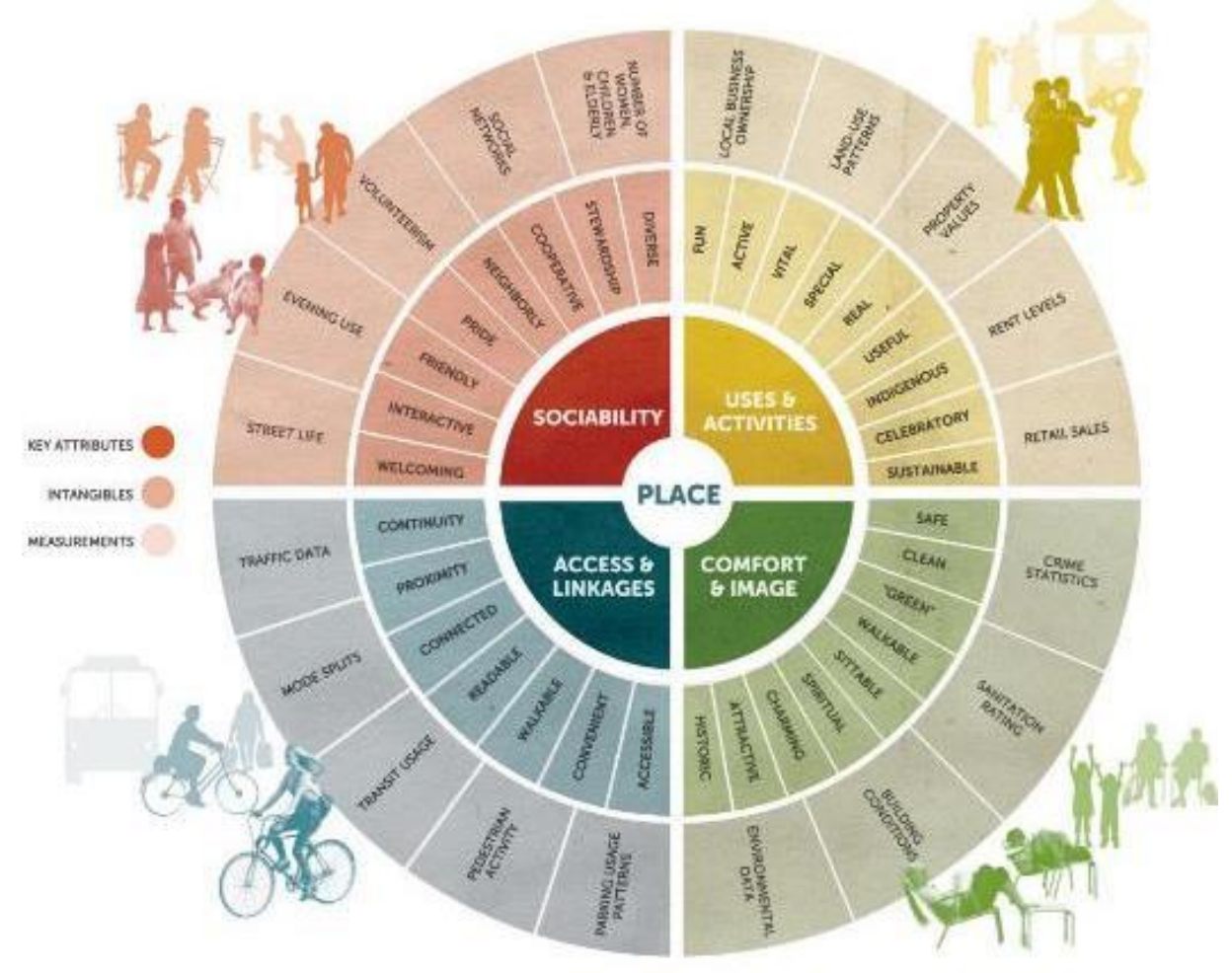

Gambar 4. What Makes A Successful Place?

Sumber: https://www.pps.org/

\section{METODE}

Dalam mendesain suatu ruang ketiga yang mewadahi kebutuhan masyarakat di suatu kawasan, penulis mencoba menyusun langkah-langkah secara garis menuju desain, seperti berikut ini ;

\section{Memperdalam teori open architecture sebagai ruang ketiga}

Dengan adanya pendukung teori yang didapat dari berbagai referensi buku maupun website (Prospect of place by Edward Relp, Space and Place : Humanistic Perspective by Yi-Fu Tuan, The Great Good Place (Third Places) by Ray Oldenburg, Teori Hirarki Kebutuhan Maslow, The Tao of Holding Space - Chris Corrigan, What Makes A Successful Place? by PPS (Project for Public Space)), penulis meringkas teori yang dibutuhkan dalam merancang open architecture sebagai ruang ketiga. 


\section{Menganalisa dan mengenal lokasi kawasan}

Dalam menganalisa lokasi tempat ketiga di kawasan terpilih dengan cara;

- Posisi kawasan terhadap jabodetabek.

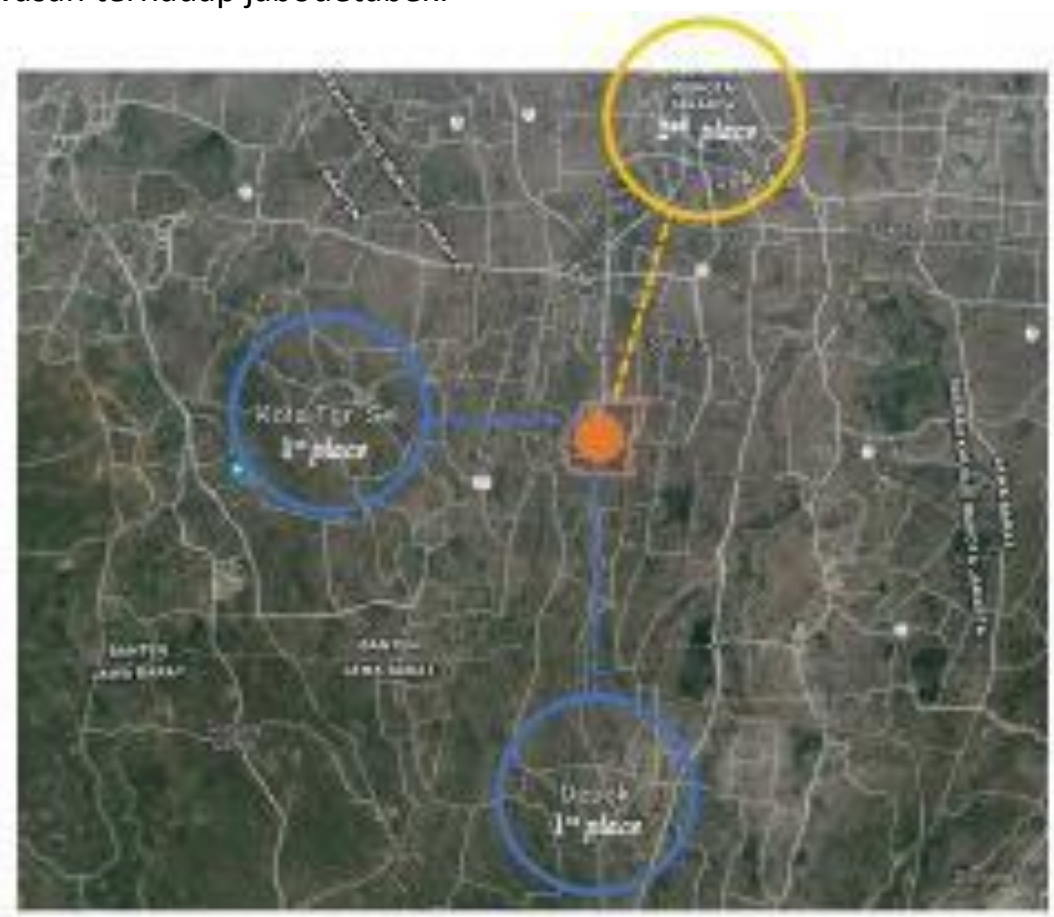

Gambar 5. Posisi Cilandak Barat Terhadap Jabodetabek Sumber: Penulis, 2019

- Perkembangan infrastruktur kawasan baik jalan, transportasi dan fasilitas bangunan pendukung, serta letak tapak terpilih dipertimbangkan dengan peraturan, lokasi terhadap jalan utama, jarak menuju transportasi dan fasilitas umum terdekat.

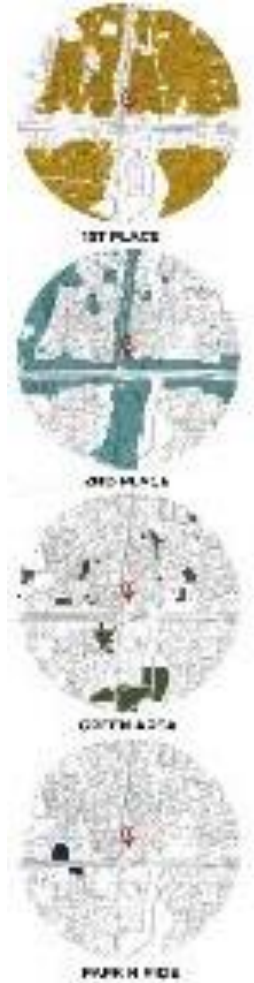

Gambar 6. Surrounding development Sumber: Penulis, 2019

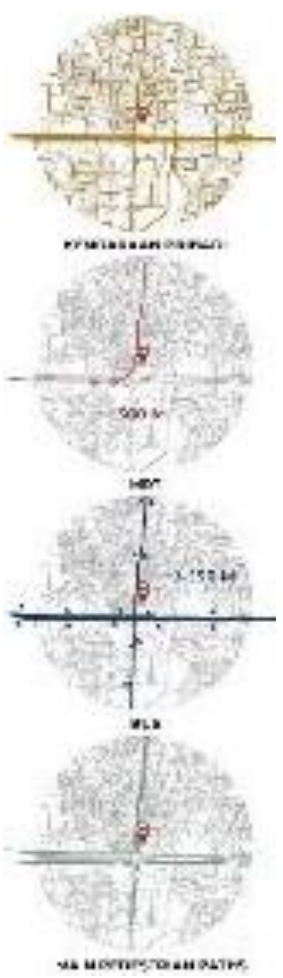

Gambar 7. Accessibility Sumber: Penulis, 2019 


\section{Mencari perilaku dan budaya masyarakat}

Poin-poin dibawah ini mendukung penulis dalam memahami tempat ketiga yang diperlukan kawasan Cilandak melalui kegiatan keseharian masyarakat Cilandak, yaitu;

- Mengenal sejarah kawasan terpilih.

- Mengenal bangunan di koridor utama dengan pemetaan

- Memetakan tempat ketiga yang sudah tersedia.

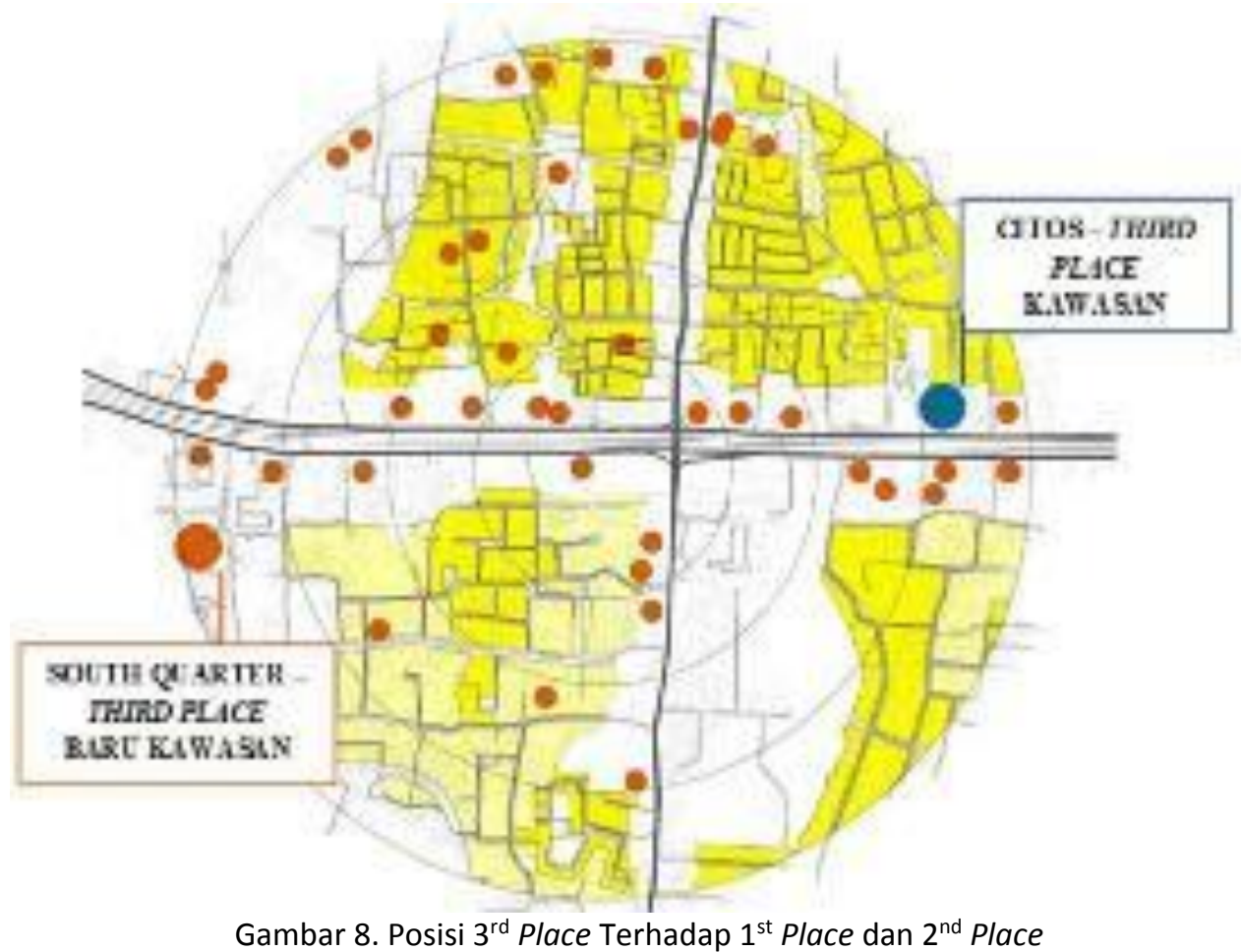

Gambar 8. Posisi $3^{\text {rd }}$ Place Terhadap $1^{\text {st }}$ Place dan $2^{\text {nd }}$ Place Sumber: Penulis, 2019

- Mencari fungsi dan event yang disediakan di tempat ketiga yang sudah tersedia.

- Konsep secara arsitektur di tempat ketiga yang sudah tersedia.

- Mengidetifikasi suatu masalah dari tempat ketiga yang sudah tersedia.

- Menyimpulkan kekuatan/ potensi kawasan dan kelemahan kawasan Cilandak Barat.

\section{Pengumpulan program}

Pengumpulan program dan ide-ide yang dikumpulkan dari hasil pemahaman perilaku dan budaya masyarakat serta analisa kawasan dan tapak terpilih.

\section{Mempertimbangkan program yang tepat}

Dari banyaknya usulan program dan ide, penulis mencoba mempertimbangkan program sehingga proyek dapat menjawab tema open architecture - architecture for the third place dengan batas-batas, yaitu;

- Sesuai dengan 7 katakteristik third place (neutral, they are level, conversation is the main activity, accessible, have regulars, physically plain and unpretentious, playful).

- Third place yang dapat menjadi suatu kebutuhan masyarakat, baik individu maupun keloompok yang terdapat dalam teori Hirarki Kebutuhan Maslow.

- Suatu third place yang menjadi ruang publik yang hidup sesuai dengan diagram 'What Makes A Successful Place?' by PPS (Project for Public Space). 


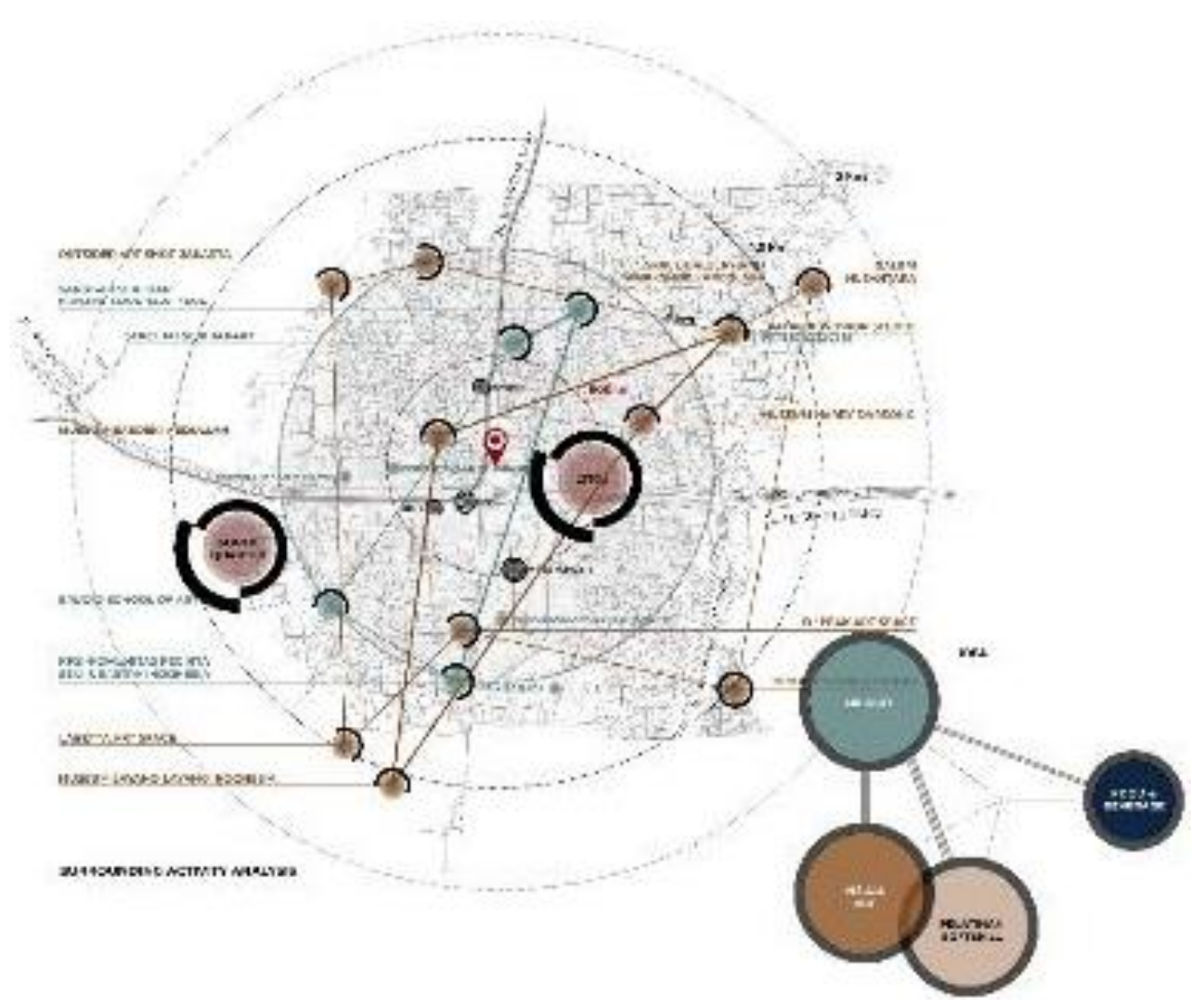

Gambar 9. Pengumpulan kegiatan pada kawasan Cilandak Barat

Sumber: Penulis, 2019

\section{Melaksanakan program dan ide-ide yang dikumpulkan}

Rencana besaran tapak dan program yang tersedia, akan dihitung menyesuaikan dengan peraturan tapak. Besaran tiap program yang tersedia akan disusun berdasarkan kelompok program yang ditandai dengan 3 area, yaitu:

- Main program

- Side program

- Service

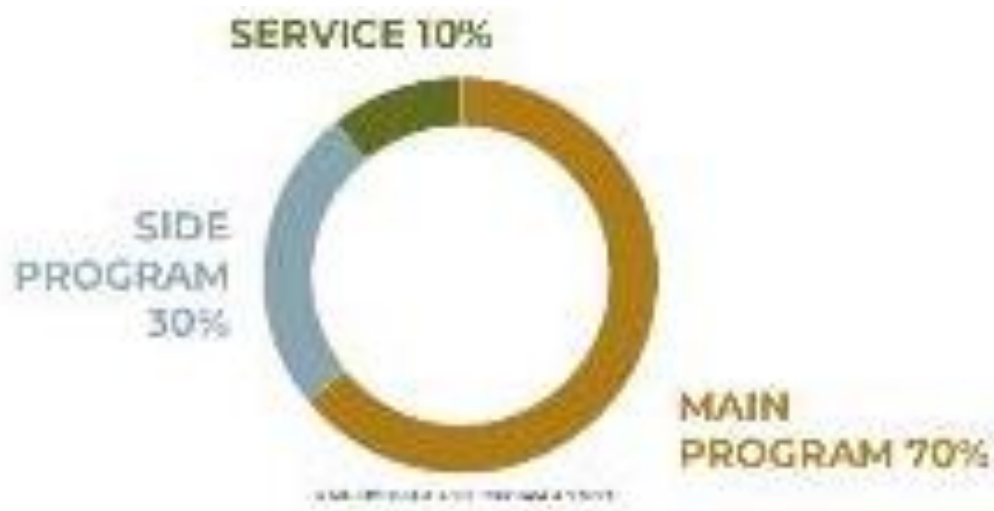

Gambar 10. Besaran program proyek

Sumber: Penulis, 2019

\section{Mulai mendesain}

Langkah terakhir yaitu zonning yang disesuaikan dengan bentuk tapak. Dari pengelompokkan ruang yang sudah ditandai dengan ketiga area yang berbeda, memudahkan penulis dalam mengatur letak dan posisi yang akan di terapkan ke dalam tapak terpilih. 


\section{DISKUSI DAN HASIL}

Berdasarkan analisa yang telah didapatkan dan dipelajari dari kawasan/ lingkungan sekitar, menghasilkan beberapa faktor pembentuk gubah massa, yaitu;

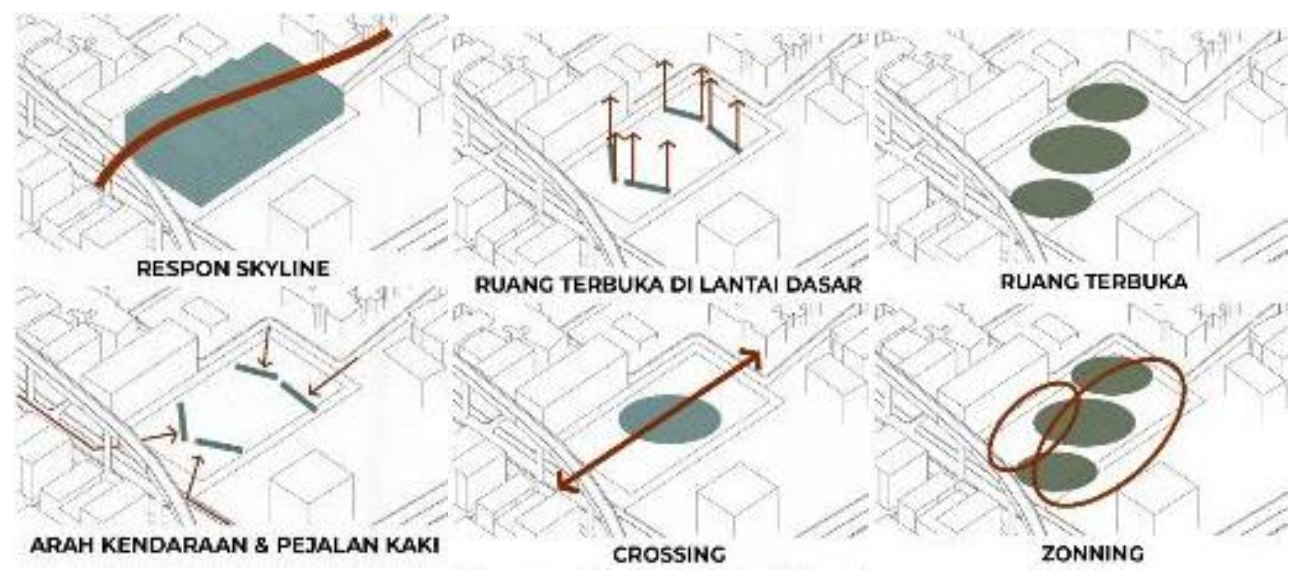

Gambar 11. Faktor pembentuk massa

Sumber: Penulis, 2019

Dari faktor gubahan massa, terciptalah massa dan konsep arsitektur sebagai pelengkap dalam desain bangunan ini. Sebuah ruang ketiga baru di Cilandak dengan menerapkan konsep keterbukaan yang disediakan bagi masyarakat sekitar untuk digunakan secara bebas dalam berekspresi. A.R.C Space yang mengandung unsur apresiatif, rekreatif dan kreatif memberikan keleluasaan dalam menggunakan fasilitas yang ada. Fasilitas-fasilitas yang disediakan mencakup studio 3D (clothing studio dan pottery studio), studio 2D (painting studio, DKV studio dan product design studio), perpustakaan, ruang pelatihan softskill dalam mendukung ekonomi kreatif di wilayah sekitar dan area food and beverage. Sesuai dengan konsep yang akan diterapkan, setiap unsur ruang akan berhubungan langsung dengan ruang luar dan memaksimalkan sistem pengudaraan alami.

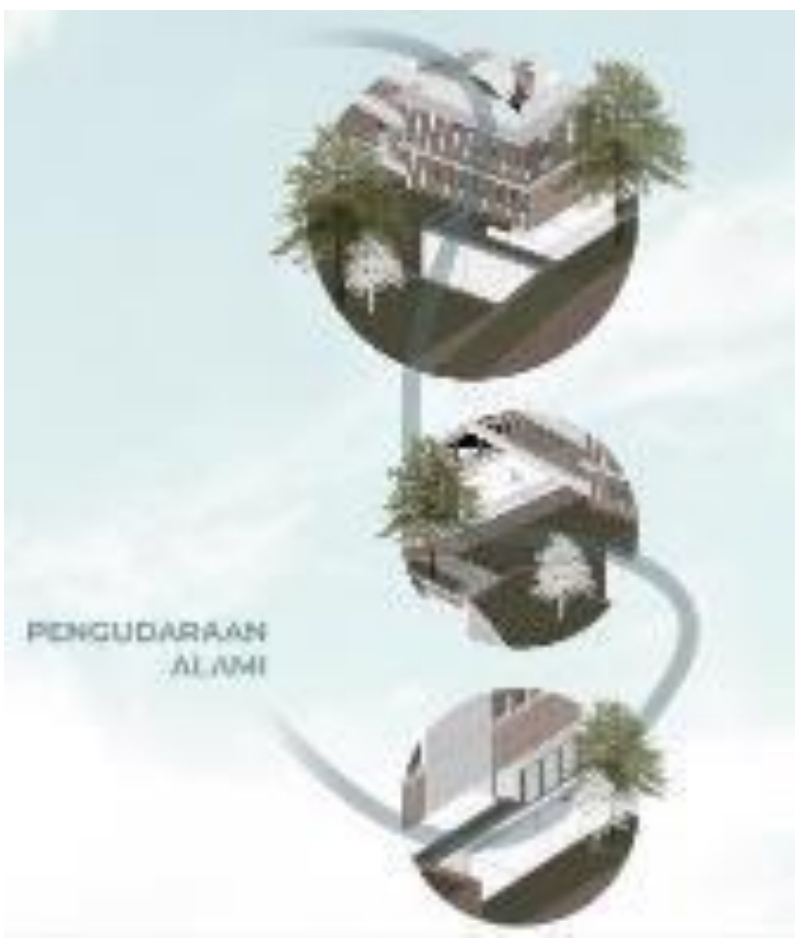

Gambar 12. Konsep Arsitektur

Sumber: Penulis, 2019 


\section{KESIMPULAN DAN SARAN}

Pada proses perancangan ini, penulis berusaha untuk menerapkan fungsi sebuah third place yang tepat dalam memenuhi atau melengkapi kebutuhan masyarakat di Cilandak Barat. Cilandak Barat sebagai kawasan yang akan menjadi CBD baru, menjadi tantangan bagi masyarakat untuk meningkatkan kesejahteraan dan kualitas sehingga mempunyai daya saing yang tinggi. Banyak kegiatan pelatihan yang sudah dilakukan oleh warga, akan tetapi kegiatan hanya dilakukan jika ada penyelenggara dikarenakan tidak/ kurangnya tempat bagi warga untuk belajar dan berkreativitas.

Banyaknya usia produktif di Kelurahan Cilandak Barat serta keingintahuan tentang mempelajari hal baru, membutuhkan fasilitas yang memadai atau third place. Sebagai third place dalam memfasilitasi dan memenuhi kebutuhan masyarakat, akan dirancang 'Cilandak Creative Hub'. Third place pada Kelurahan Cilandak Barat, akan menawarkan third place dengan kategori edutainment.

Tempat dimana masyarakat dapat menyalurkan ide sebebas-bebasnya dan bersosialisasi bertemu orang-orang dan komunitas baru melalui program yang disediakan yaitu seni dan pelatihan kewirausahaan dalam mendukung ekonomi kreatif. Third place sebagai tempat bersenang-senang dan belajar dimana berpartisipasi dalam memajukan ekonomi kreatif, turut mendukung program SDG (Sustainable Development Goals). Berikut merupakan poin - poin terpilih pada program SDG, yaitu:

\section{REFERENSI}

BEKRAF. (n.d.). Tonggak Baru Ekonomi Kreatif Indonesia. Retrieved from BEKRAF: https://bekraf.go.id/profil

C, A. (2012, May 7). Kawasan CBD Baru di Jaksel. Retrieved from okefinance: https://economy.okezone.com/read/2012/05/07/471/624864/kawasan-cbd-baru-di-jaksel

Enggie. (2008, September 1). TINJAUAN TEORI RUANG TERBUKA (OPEN SPACE). Retrieved from enggie-architect: http://enggie-architect.blogspot.com/2008/09/tinjauan-teori-ruangterbuka-open-space.html

INSTITUTE, I. L. (2019). A Visionary Path to a Regenerative Future. LIVING COMMUNITY CHALLENGE HANDBOOK.

Jameel Arts Centre Dubai / Serie Architects. (2018, November 21). Retrieved from ArchDaily: https://www.archdaily.com/906190/jameel-arts-centre-dubai-serie-

architects?ad_medium=gallery

Mauliani, L. , dkk (2013). Kajian Jalur Pedestrian Sebagai Ruang Terbuka pada Area Kampus. (2013, July). Retrieved from ResearchGate: https://www.researchgate.net/publication/276278685 KAJIAN JALUR PEDESTRIAN SEBA GAI RUANG TERBUKA PADA AREA KAMPUS. Jurnal Arsitektur NALARS 12(2): 1-9.

Kennedy Center for Theatre and the Studio Arts / Machado and Silvetti Associates. (2015, May 28). Retrieved from ArchDaily: https://www.archdaily.com/635562/kennedy-center-fortheatre-and-the-studio-arts-machado-and-silvetti-associates?ad_medium=gallery

Kondisi Wilayah. (n.d.). Retrieved from Situs Resmi Kecamatan Cilandak: http://selatan.jakarta.go.id/kecamatan_cilandak/?page=Kondisi.Wilayah

Koran SINDO, J. (2017, January 11 ). Kawasan Paling Favorit di Jakarta Selatan. Retrieved from okefinance: https://economy.okezone.com/read/2017/01/11/470/1588503/kawasanpaling-favorit-di-jakarta-selatan

LinkedIn. (2018). Perceptions of access and barriers to opportunity in Asia Pacific. LinkedIn Opportunity Index 2018.

P, A. H. (2019 , April 6). MRT Jakarta Dongkrak Nilai Properti. Retrieved from SUARA: https://www.suara.com/foto/2019/04/06/170219/mrt-jakarta-dongkrak-nilaiproperti?page $=2$

P, A. H. (2019, April 6 ). MRT Jakarta Dongkrak Nilai Properti. Retrieved from SUARA: https://www.suara.com/foto/2019/04/06/170219/mrt-jakarta-dongkrak-nilai- 